According to the numbers above, the ratio of the direct anthropogenic contributions to the observed sea-level rise has increased during the past 100 years up to the actual ratio of 0.31 . Thus, would an integration over, for instance, the next 50 years point towards an important role of human activities in sea-level rise during that period? This seems not to be the case: Sahagian et al. compute a sea-level rise due to human activities in the next 50 years of $26.1 \mathrm{~mm}$. The IPCC report $^{2}$ predicts a sea-level rise due to climaterelated factors (thermal expansion of the oceans and volume change of land ice) of $210 \mathrm{~mm}$, giving $11 \%$ for the contribution of human activities.

I also disagree with the statement that, finding 30\% for the direct anthropogenic contributions to sea-level rise in the twentieth century, "the contributions of glacial melting and ocean thermal expansion are smaller than previously thought". No reference is given. According to the IPCC report ${ }^{2}$, observed sea-level rise over the past 100 years is $15 \pm 5 \mathrm{~cm}$ and the sum of estimates of the climate-related contributions is $10.5 \pm 11 \mathrm{~cm}$. Disregarding the uncertainties, these values allow for a contribution of exactly $30 \%$ by other factors than the climate-related ones. After reading Sahagian et al., I understand that $7 \%$ can be attributed to groundwater withdrawal, surface-water diversion and land-use changes.

\section{Wouter Greuell}

Institute forMarine and Atmospheric

Research,

Utrecht University, Princetonplein 5. 3584 CC Utrecht, The Netherlands

SAHAGIAN ET $A L$. REPLY - Greuell suggests that past sea-level changes integrated over long periods of time are more interesting than actual rates. We disagree and maintain that the current rate of sea-level change induced by humans is the datum of greatest interest for comparison with climate-induced changes in sea level, because it provides the basis for extrapolation into the future. Our figure of $30 \%$ pertains to the present rate of rise caused by anthropogenic factors, compared with the total measured rate as averaged over twentieth-century tide gauge records.

There are two reasons that the current rate of anthropogenic sea-level rise is larger than the average rate throughout this century. First, the rate of anthropogenic contributions has increased throughout this century, apart from a temporary reduction due to major dambuilding projects in the 1960s and 1970s. Second, the major dam-building activities reduced the twentieth-century average, but have now virtually ceased. The present rate of $0.54 \mathrm{~mm}$ per yr is thus not an average of all anthropogenic factors since 1960 because it does not include dams.
Indeed, this figure is a conservative underestimate, as the trend of increasing rates would suggest that the present rate is greater than the average over the past 34 years. Similarly, the present rate $(0.54$ $\mathrm{mm}$ per yr) provides a conservative basis for future extrapolation as it assumes that the anthropogenic contributions will cease the pattern of increase exhibited throughout the twentieth century.

Greuell cites an IPCC report $^{2}$ for future sea-level rise due to climate factors which is based on various models and predicts a much greater contribution in the future than has been observed in the past (or present). It follows that when compared this way, he obtains a low figure of $11 \%$ for the anthropogenic contribution. One could take into account projected increases in water needs of the growing human population and calculate a larger percentage. We are reluctant to do this because the uncertainties in local and global economics, development of arid and forested regions and many other factors make such projections unreliable.

Greuell makes an argument based on

"disregarding uncertainties" in the IPCC estimate $^{2}$ of climate-related contributions of $10.5 \pm 11 \mathrm{~cm}$. We feel that uncertainties which are larger than the magnitude of inferred sea-level rise cannot be disregarded, and that this figure cannot be used for reliable projections. Our efforts have been directed at identifying additional factors which must be considered before estimates of climate contributions to sea level can be deduced from measured sea-level rise.

D. L. Sahagian*

D. K. Jacobs ${ }^{\dagger}$

F. W. Schwartz ${ }^{\ddagger}$

* Byrd Polar Research Center.

${ }^{\star}$ Department of Geological Sciences,

Ohio State University,

Columbus, Ohio 43210, USA

'Department of Biology,

University of California,

LosAngeles,

California 90024, USA

1. Sahagian, D. etal. Nature 367, 54-56 (1994).

2. Warrick, R. \& Oerlemans. J. in Climate Change. The IPCC Scientific Assessment (eds Houghton, J., Jenkins, G. \& Ephraums, J.) 257-282 (Cambridge Univ. Press. 1990).

\title{
Pore region of $\mathrm{K}^{+}$channel RACTK1
}

SIR - Suzuki et al. ${ }^{1}$ have published the sequence of a potassium channel involved in the secretion of $\mathrm{K}^{+}$from the renal collecting duct. This channel is inhibited by protons, explaining the wellestablished competition between $\mathrm{K}^{+}$and

hydropathy plot, and using the program CAMELEON (Oxford Molecular Ltd), would give the result shown in the bottom row of the sequence comparison below, Ala 181 being underlined in both top and bottom rows. This alignment also gives a

$\begin{array}{ll}\text { RACTK1 (residues 168-189) } & \text { WHMGFFLSSILPASGKLVSTTA } \\ \text { IRK1 (132-153) (ref. 2) } & \text { AFLFSIETQTTIGYGFRCVTDE } \\ \text { GRR1 (133-154) (ref. 3) } & \text { AFLFFIETEATIGYGYRYITDK } \\ \text { ROMK1 (131-152) (ref. 4) } & \text { AFLFSLETQVTIGYGFRFVTEQ } \\ \text { RACTK1 (modified alignment; } & \text { ASGKLVSTTAT IFFGSDLNIAG } \\ \text { 181-202) } & \end{array}$

$\mathrm{H}^{+}$, and by ATP ${ }^{1}$ The authors offered a suggested alignment of their channel sequence with that of other related channels from the family containing the inward rectifiers IRK1 (ref. 2) and GIRK1 (ref. 3 ), and another channel from renal tubule, ROMK1 (ref. 4). These channels apparently have in common the possession of only two membrane-spanning $\alpha$ helices.

So far as the so-called H5 or P (poreforming) region of the channel is concerned, the alignment suggested by Suzuki et al. ${ }^{1}$ is as shown above.

But an alignment more consistent with what is known of this region in other $\mathrm{K}^{+}$ channels is achieved if the constraint is imposed that the motif TXXT, common also among voltage-gated $\mathrm{K}^{+}$channels (see, for example, ref. 3), is conserved. Carrying out an alignment with this constraint, informed by a Kyte-Doolittle conserved Gly (position 195) following Phe in place of Tyr in other $\mathrm{K}^{+}$channels. Note that the ion channel asssociated with the ether-a-go-go mutation of Drosophila has Phe in place of Tyr in an equivalent position ${ }^{5}$, but this channel permits $\mathrm{Ca}^{2+}$ as well as $\mathrm{K}^{+}$permeance ${ }^{6}$. Our proposed alignment suggests that RACTK1 is more closely related to other channel types than proposed by Suzuki et al. ${ }^{\mathrm{I}}$.

\section{J. Sutcliffe}

Biological NMR Centre,

P. R. Stanfield

Department of Cell Physiology and

Pharmacology, University of Leicester,

POBOX 138, Leicester LE1 9HN, UK

\footnotetext{
1. Suzuki, M. etal. Nature 367, 642-645 (1994).

2. Kubo, Y. etal. Nature 362, 127-133 (1993).

. Kubo, Y. et al. Nature 364, 802--806 (1993).

Ho, K. et al. Nature 362, 31-38 (1993).

Warmke, J. et al Science 252, 1560-1562 (1990).

Brüggeman A et al Nature $365,445-448$ (1993).
} 